\title{
Responsabilidad penal de los órganos de dirección de la Empresa por comportamientos omisivos. El deber de garante del empresario frente a los hechos cometidos por sus subordinados
}

Iván Fabio Meini Méndez

\section{Introducción: el problema}

1. En el derecho penal económico, la criminalidad de empresa, más que la criminalidad en la empresa, de un tiempo a esta parte, ha acaparado la atención de la doctrina. ${ }^{1}$ Tal vez, esta tendencia responda al hecho que los clásicos criterios de atribución de responsabilidad penal (principalmente el entender "agotada" la imputación al recaer ésta sobre los ejecutores directos del hecho ${ }^{2}$ ), así como el monopolio que en

1 La criminalidad de empresa (Unterenehmenskrimimalität), en palabras de Schünemann, comprende a los delitos económicos en los que "por medio de la actuación de una empresa se lesionan bienes jurídicos e intereses externos, incluidos los bienes jurídicos e intereses propios de los colaboradores de la empresan, mientras que la criminalidad en la empresa (Bretiebskriminalität) comprende los comportamientos lesivos de "colaboradores de la empresa a la misma o a otros de sus colaboradores". "Cuestiones básicas de dogmática jurídico-penal y de política-criminal acerca de criminalidad de empresa». Trad. Brückner y Lascuraín, ADPCP, (1988-II), pp. 530 y 531.

2 Cfr. Hassemer/Muñoz Conde. La responsabilidad por el producto en Derecho penal. Tirant lo Blanch, Valencia, 1995, pp. 174 y 175: "Lo que sí resulta aquí nuevo es la metodología utilizada, de imputar los deberes incumplidos al responsable último de la decisión (y no a quien se encuentra más próximo al hecho). La dogmática de la participación en el ámbito de la responsabilidad por el producto no se asienta, por tanto, ya en la responsabilidad del que ha provocado el daño (para luego investigar la participación o la autoría mediata "hacia arriba") sino que busca desde el primer momento quién debe responder en última instancia de ese daño», B. Schünemann, "Cuestiones [...]» op.cit., p. 531, en el marco de una empresa, o sea, de un grupo de personas organizado por medio de la división del trabajo, "la verdadera lesión del bien jurídico es llevada a cabo a menudo por una persona física que no es, en este aspecto, verdaderamente responsable o, al menos, no tiene la exclusiva responsabilidad». En el mismo sentido, M. Paredes «Problemas de la responsabilidad penal en supuestos de comercialización de productos adulterados: algunas observaciones acerca del "Caso de la 
materia de imputación de responsabilidad penal ostentan las personas naturales, ${ }^{3}$ enseñan que no siempre se satisfacen los sentimientos de prevención: las decisiones las adoptan los órganos de administración y la llevan a cabo empleados subordinados, produciéndose en la práctica una "imputación hacia abajo" con el correlativo desmedro de efectos de prevención. ${ }^{4}$

$Y$ este desmedro de efectos preventivos se origina en la fungibilidad de los subordinados habida cuenta de la particular organización empresarial (división vertical y horizontal): en el desconocimiento del significado de las consecuencias de su acción debido a la insuficiente información que poseen respecto del funcionamiento global de la empresa; $y$, a la escasa resistencia que pueden ofrecer frente a la llamada "actitud criminal colectiva", con arreglo a la cual al interior de una empresa se manejan valores y mecanismos de presión que pueden determinar que un miembro de la empresa a consecuencia de su vinculación al establecimiento y a la notoriamente alta disposición a la obediencia del hombre en el sistema jerárquico actúe, en palabras de Schünemann, "de un modo altruista en interés de la casa», ${ }^{5}$ cuando

Colza». Hacia un Derecho Penal Económico Europeo. (Jornadas en Homenaje al Prof. Tiedemann), Madrid, 1995, pp. 289 y ss., en especial, pp. 294 y ss.

3 El concebir que las personas jurídicas son sujetos incapaces de set sancionados por el derecho penal es, como se sabe, una teoría que en la actualidad se pone en tela de juicio en atención a una serie de consideraciones político-criminales. Con atención a la realidad nacional, Cfr. I. Meini Méndez, La responsabilidad penal de las personas jurídicas. Fondo Editorial de la Pontificia Universidad Católica de Perú, Lima, 1999, pp. 143 y ss.; “Responsabilidad penal de las personas jurídicas y de sus órganos de gestión. Entre la dogmática y la política criminal». Ius et Veritas, (VII-13), 1996, pp. 190 y ss., J. Hurtado Pozo, "Personas jurídicas y responsabilidad penal". Anuario de Derecho Penal, Lima, 1996, pp. 141 y ss.

4 C. Martínez-Buján, Manual de Derecho penal económico. Parte General, Tirant lo Blanch, Valencia, 1998, p. 197 y B. Schünemann, "Cuestiones...». op.cit., p. 533.

5 B. Schünemann, «Cuestiones...». op. cit., pp. 529 y 533; "La punibilidad de las personas jurídicas desde la perspectiva europea». Hacia un Derecho Penal económico Europeo (Jornadas en homenaje al Prof. Tiedemann), Madrid, 1995, pp. 571 y 572 . Asumen este planteamiento, V. Militello, «La responsabilidad jurídico-penal de la empresa y de sus órganos en Italia». Fundamentos de un Sistema Europeo del Derecho Penal. Libro Homenaje a Claus Roxin, Bosch, Barcelona, 1995, (Silva Sánchez, ed. Española), p. 411, Terradillos, J. Derecho penal de la empresa. Trotta, Madrid, 1995, p. 39, quien se refiere a la actitud criminal colectiva como "escasa capacidad de resistencia frente a la actitud prodelictiva del grupo por parte de quien, como regla, está obligado a obedecer dentro de una escala jerarquizada" y J. M. Silva Sánchez, "Criterios de asignación de responsabilidad penal en estructuras jerárquicas". Cuadernos de Derecho Judicial: Empresa y delito en el Nuevo Código Penal, (1997), pp. 32 y ss., para quien «[...] el empleado subalterno, el subordinado en general, 
objetivamente está realizando una conducta prohibida por el derecho penal. ${ }^{6}$

Las mencionadas exigencias de prevención podrán satisfacerse en tanto la imputación penal recaiga, también, sobre los delincuentes en sentido criminológico, es decir, sobre los órganos de dirección de la empresa que, gracias a su ubicación privilegiada en el engranaje empresarial, tienen acceso a los medios e instrumentos necesarios para encausar el iter criminal, aunque lo cierto es que la consecución de este objetivo no significa que se tengan que adoptar parámetros objetivos de imputación de responsabilidad penal.

2. Ante este panorama se pueden distinguir dos ámbitos de estudio. Por un lado, la responsabilidad que le cabe al subordinado por el delito que materialmente comete, responsabilidad que no tiene porqué ofrecer problemas ya que se le podrá calificar de autor, coautor, autơr accesorio, e incluso, como cómplice, en caso haya participado en el delito que ejecuta el titular como autor. ${ }^{8}$ Por otro lado, la responsabilidad omisiva del titular por el comportamiento del subordinado, lo que ofrece, a diferencia de lo anterior, problemas sustantivos derivados del hecho de que los subordinados constituyen "engranajes" en la

puede encontrase inmerso en un determinado clima (que algunos criminólogos llaman "actitud criminal de grupo") en el que la exacerbación del principio del interés de la empresa, así como la estructura organizativa jerárquica, relativicen su capacidad de oponerse a la ejecución de hechos delictivos que por otros le viene propuestos [...] las personas pierden el estímulo motivatorio para no realizar una determinada conducta, siempre que puedan imputar las consecuencias de su conducta a un tercero al que harán psicológicamente responsablen.

6 Así, J.M. Silva Sánchez, "Responsabilidad penal de las empresas y de sus órganos en Derecho español". Fundamentos de un Sistema Europeo del Derecho Penal, Libro Homenaje a Claus Roxin, (Silva, ed. Española), Bosch, Barcelona, 1995, p. 368.

7 Incluso si se trata de un delito especial, se le puede y debe considerar cómplice del mismo aún cuando no ostente la cualificación que exige el tipo, ya que la participación es siempre colaboración en un delito ajeno, respetándose, de esta manera, la unidad del título de imputación. Cfr. Quintero/Morales/Prats, Manual de Derecho penal. Parte General. Aranzadi, Pamplona, 1999, p. 631, D-M. Luzón Peña, Curso de Denecho penal I. Editorial Universitas S.A., Madrid, 1996, p. 305, Arán Muñoz Conde/García, Derecho penal. Parte General. $3^{a}$ ed.,Tirant lo Blanch, Valencia, 1999, pp. 498 y ss., B. Feijóo, Límites a la participación criminal ¿existe una "prohibición de regreso" como límite general del tipo en derecho penal. Comares, Granada, 1998, pp. 4 y ss.

8 H. Achenbach, "Sanciones con las que se puede castigar a las empresas y a las personas que actúan en su nombre en el derecho alemán». Fundamentos de un Sistema Europeo del Derecho Penal. Libro Homenaje a Claus Roxin. Bosch, Barcelona, 1995, (Silva, ed. Española), p. 383, J.M. Silva Sánchez, "Responsabilidad [...]». Cit., pp. 369 y ss. y C. Martínez-Buján, Op. cit., p.198. 
maquinaria empresarial y en la mayoría de los casos desconocen el sentido final de la operación a la cual contribuyen con una simple aportación causal," situación que importa, asimismo, que la lesión del bien jurídico aparezca como resultado cumulativo de la confluencia de una serie de conductas no dolosas de dos o más personas, o aparezca como un imprudente "fallo técnico". ${ }^{10}$

Y como quiera que la indagación y determinación de los responsables se inicia de abajo hacia arriba, esto es, se empieza por los estratos inferiores de la empresa (empleados subordinados que serán los ejecutores materiales) y se sube por el escalafón jerárquico hasta llegar a los titulares que ostentan la dirección del ente colectivo, no parece aconsejable mantener la teoría de la "prohibición de regreso", en cuya virtud no hay necesidad de seguir escalando en busca de más responsables en tanto se haya encontrado ya alguno, sino que, por el contrario, se tiene que apelar a los criterios de imputación objetiva e imputación subjetiva, por un lado, y a las reglas sobre autoría y participación, por otro. ${ }^{11}$

Del mismo modo, la responsabilidad del empresario tiene que contrastarse con el riesgo implícito de toda actividad empresarial que se deriva de los propios medios y recursos que utiliza $(v \cdot g r$. maquinaria pesada, exposición de los trabajadores a sustancias potencialmente tóxicas, colocación en el mercado de un producto de consumo defectuoso, etc. vid, infra III.2), de donde se deduce que éste responderá, bien por los daños que sufran las propias personas que trabajan en y para la empresa -lo que generará la responsabilidad del empresario como empleador- $-{ }^{12}$ bien por los daños que se manifiesten en el exterior,

\footnotetext{
9 Por ejemplo, el chofer de una empresa a quien le ordenan deshacerse de las materias primas «sobrantes» y las verte en un río, sin saber que el directorio de la compañía productora de cemento para cual presta servicios cuenta con su "ciega" obediencia para deshacerse de los residuos tóxicos.

10 J. M. Silva Sánchez, La expansión del Derecho penal. Aspectos de política-criminal en las sociedades postindustriales. Madrid, Civitas, 1998, p. 22 y ss.

11 Así, B. Feijóo, Op. cit., p. 11.

12 Piénsese, por ejemplo, en la modalidad de delito contra los derechos de los trabajadores de obligar a otro a trabajar sin las condiciones de seguridad e higiene industriales determinadas por la autoridad, del Art. $168.3 \mathrm{CP}$ e, incluso, la atribución de una muerte a título de negligencia en la medida en que el deceso resulte de la inobservancia de reglas técnicas de profesión, ocupación o industria, del Art. 1110 CP.
} 
como los delitos contra la ecología, contra la Salud Pública o, en general, en la llamada responsabilidad penal por el producto. ${ }^{13}$

\section{El método}

1 La organización interna de la empresa, en tanto cúmulo de aportaciones de todos sus miembros dirigidas por igual a la consecución del objeto social, tiene que garantizar su eficacia y competitividad, lo que genera que las diversas entidades colectivas se hayan organizado de modo altamente complejo.

En consecuencia, la estructura empresarial importa, como pilar organizativo elemental, (i) desde un plano vertical, la división del trabajo, la especialidad y la complementariedad, con arreglo a lo cual cada quien que interviene en el proceso de producción asume una determinada competencia funcional y realiza una aportación que complementa, y se complementa a su vez, con las aportaciones de los sujetos restantes en el contexto de un plan común; y, (ii) desde un plano horizontal, el respeto al principio de jerarquía, en cuya virtud las aportaciones de cada cual están sometidas a una común dirección, que puede aceptarlas, modificarlas o rechazarlas. ${ }^{14}$ Acorde con ello, es lógico entender que en estas estructuras jerárquicas la información y decisión, que ostentan los empresarios, no coincide en la misma persona que lleva a la práctica los actos de ejecución de la conducta penalmente relevante, es decir, en los subordinados. ${ }^{15}$

13 E. Bacigalupo, "La posición de garante en el ejercicio de funciones de vigilancia en el ámbito empresarial». Cuadernos de Derecho Judicial: La responsabilidad penal de las sociedades. Actuación en nombre de otro. Responsabilidad de los consejos de administración. Responsabilidad de los subordinados, (1994-VII), Madrid, pp. 63 y 64, Hassemer/ Muñoz Conde. Op. cit., pp. 56 y ss. y Ma.P. Batista «La responsabilidad penal de los órganos de la empresa". Curso de derecho penal económico (Bacigalupo, dtor), Madrid, Marcial Pons, 1998, p. 87.

14 Por todos, J. Paredes Castańón, «Problemas...» op. cit., pp. 294 y ss. y 306 y ss.; Paredes/Rodriguez. El caso de la colza: responsabilidad penal por productos adulterados o defectuosos, Valencia, Tirant lo Blanch, 1995, pp. 142 y ss.

15 Ya lo puso de relieve Schünemann ("Cuestiones [...]". op. cit., p. 533) al describir acertadamente las relaciones entre acción y responsabilidad en las instituciones jerárquicas «como consecuencia del principio de descentralización, característico en la organización de la 
La secuela inmediata es que, pese a la unidad de dirección, los centros de decisión y de responsabilidad se diferencian: ${ }^{16}$ deciden unos (los titulares) y responden otros (los empleados) y conlleva, además, la dificultad de identificar al sujeto individual responsable del comportamiento delictuoso acaecido en el seno de una persona jurídica para la cual actúa y, por ende, de imputarle responsabilidad penal. ${ }^{17}$

2 Así las cosas, pareciera que la categoría de la autoría mediata podría ser utilizada para imputar responsabilidad penal al titular en tanto el subordinado aparece como un «instrumento», empero, hay que tener en cuenta que muchas veces el subordinado será ya autor directo y, como tal, penalmente responsable, sin contar los supuestos en que el subordinado inmediatamente dependiente en la escala jerárquica es, a su vez, ya un autor mediato plenamente responsable. ${ }^{18}$ Con todo, la teoría del "autor detrás de autor» que formulara Roxin sobre la base de los casos Eichmann y Straschynski de la II Guerra Mundial, en cuya función se puede afirmar la autoría mediata de quien ostenta el dominio de la voluntad en aparatos organizados de poder -ya no por existir un dominio por coacción o error, sino sobre la base de la fungibilidad del ejecutor material y en la circunstancia de que el «autor detrás del autor» puede dirigir la parte de la organización que le está subordinada sin tener que dejar a criterio de otros la realización del delito- ${ }^{19} \mathrm{y}$, en consecuencia, sirve para abordar estos supuestos.

empresa moderna, de la transformación de la función de poder y de decisión de las altas instancias, por él condicionada, la "organización de la responsabilidad"-por decirlo con una expresión tópica- amenaza convertirse en una "organizada irresponsabilidad", lo que desde un punto de vista jurídico-penal se expresa a través de un cambio de la imputación del hecho hacia abajo, si no hacia los miembros de la organización que están más abajo, ya que sólo ellos llevan a cabo por sí mismos la actuación tipificada en el supuesto de hecho penal o administrativo". En el mismo sentido, J. Terradillos, op. cit., Pp. 38 y ss.

16 J. Hurtado Pozo, op. cit., p. 144.

17 J.M. Zugaldía, "Conveniencia político-criminal e imposibilidad dogmática de revisar la fórmula tradicional societas delinquere non potests. Cuadernos de política Criminal, (1980-11), pp. 83 y ss., J.M. Silva Sánchez, «Responsabilidad [...]». Op. cit., p. 363, C. Martínez-Buján, op. cit., p. 233 y I. Meini Méndez, La responsabilidad [...] op. cit., pp. 150 159.

18 J.M. Silva Sánchez, "Responsabilidad [...]». Op. cit., p. 370; "Criterios de asignación [...]" op. cit., p. 39 y C. Martínez Buján, Op. cit., p. 200.

19 C. Roxin, Autoría y dominio del hecho en Derecho penal. Trad. De la $6^{a}$ de. A cargo de Cuello Contreras y González de Murillo, Madrid, Marcial Pons, 1994, pp. 267 y ss., en especial, pp. 270,273 y 274. 
Esta construcción dogmática parecería ser compatible con el diagnóstico ofrecido, en el sentido de que al subordinado no le falta ni la libertad ni la responsabilidad del ejecutor directo, por lo que responde como autor culpable y de propia mano. ${ }^{20}$ Lo que sucede es que "estas circunstancias son irrelevantes para el dominio por parte del sujeto de detrás, porque desde su atalaya el agente no se presenta como persona individual libre y responsable, sino como figura anónima y sustituible. El ejecutor, si bien no puede ser desbancado de su dominio de la acción, sin embargo es al mismo tiempo un engranaje -sustituible en cualquier momento- en la maquinaria del poder, y esta doble perspectiva impulsa al sujeto de detrás, junto a él, al centro del acontecer». ${ }^{21}$

Ello no obstante, se perciben ciertas dificultades para aceptar este planteamiento. Jescheck se muestra reacio a aceptar esta categoría con carácter general, ya que, como quiera que se trata de una modalidad de autoría mediata, serviría solamente cuando los propios ejecutores no puedan ser considerados como autores plenamente responsables, ya que si lo fueran el «autor de la mesa de escritorio» sería coautor al dominar la organización, siendo que el carácter común de la decisión respecto a la realización del hecho viene dado por la pertenencia a la organización. ${ }^{22}$ En similar sentido se ha pronunciado Gimbernat, al considerar cómplices a todos los sujetos iñtermedios que se encuentran entre quien desde arriba da la orden y el ejecutor. ${ }^{23}$ Téngase en cuenta, además, los supuestos en que no resulta pacífico hablar de autoría

20 Ibidem. p. 270: «una organización así despliega vida independiente de la identidad variable de sus miembros. Funciona "automáticamente», sin que importe la persona individual del ejecutor. Basta con tener presente el caso, en absoluto de laboratorio, del gobierno, en un régimen dictatorial, que implanta una maquinaria para eliminar a los desafectos o a grupos de personas. Si dada esa situación (por expresarlo gráficamente) el sujeto de detrás que se sienta a los mandos de la estructura organizativa aprieta el botón dando la orden de matar, puede confiar en que la orden se va ha cumplir sin que tenga que conocer al ejecutor. Tampoco es necesario que recurra a medios coactivos o engañosos, puesto que sabe que si uno de los numerosos órganos que cooperan en la realización de los delitos elude cumplir su cometido, inmediatamente otro va a suplirle, no resultando afectada la ejecución del plan global». En nuestro concepto, este diagnóstico es perfectamente trasladable a una estructura empresarial.

21 Ibidem, p. 271.

22 H.H. Jescheck, Tratado de Derecho penal. Parte General. $4^{a}$ de., trad. Manzanares Samaniego, Comares, Granada, 1993, p. 611.

23 Autor y Cómplice en Derecho penal. Sección de publicaciones e intercambio de la Facultad de Derecho de la Universidad de Madrid, Madrid, 1966, pp. 181 y ss., en especial, p. 185. 
mediata, como aquellos en que el dominio organizativo no sea tan intenso, o los casos de quienes en su calidad de eslabones intermedios en la cadena jerárquica sólo transmiten instrucciones desde la esfera superior a la inferior, o aquellos otros casos en que el superior favorezca, a título de dolo eventual o negligencia, el hecho del subordinado; ${ }^{24}$ sin contar los supuestos de delitos de medios determinados o de mera actividad, en donde resulta conflictivo afirmar la autoría mediata.

3 En este orden de ideas, tal parece que la estructura de la comisión por omisión es la llamada a constituirse en el fundamento de la responsabilidad del titular por los hechos cometidos por sus subordinados, en tanto ostenten «una concreta situación de competencia específica que le obligaba a controlar los factores de peligro derivada de la misma y, en consecuencia, a evitar la realización de delitos por sus subordinados en la cadena jerárquica de la empresa». ${ }^{25}$

\section{La comisión por omisión y su traslado al ámbito empresarial}

\section{Marco legal}

1 El Art. 13 CP, modificado por Ley No 26682, de 11 de noviembre de 1996, regula los delitos omisivos en su modalidad de comisión por omisión: ${ }^{26}$

24 Expresamente, J.M. Silva Sánchez, "Responsabilidad [...]", op. cit., p.371.

25 C. Martínez-Buján,. Op. cit., p. 201.

26 En doctrina se manejan dos clasificaciones de tipos de injusto omisivos. Por un lado, la omisión pura y la comisión por omisión, siendo los primeros los equivalentes a los tipos de injusto comisivos de resultado, esto es, aquellos cuya estructura típica exige que la acción vaya seguida de la causación de un resultado separable de ésta espacial y temporalmente (Vid. S. Mir Puig, Derecho penal. Parte general. $5^{\text {a }}$ ed., PPU, Barcelona, 1998, 9/28 y 9/29, E. Bacigalupo, Principios de Derecho penal. Parte General. 3a ed., Akal Iure, Madrid, 1994, pp. 257 y 258). Por otro lado, los tipos de injusto omisivos propios e impropios; dependiendo de si la ley los prevé expresamente (propios) o si se derivan -vía interpretación- de un tipo de injusto regulado por la ley en forma comisiva (impropios). Aunque también se han formulado otras clasificaciones sin perjuicio de las anteriores. Así, Roxin ( En el límite entre comisión y omisión». Problemas básicos del Derecho penal. Trad. Luzón Peña, Reus, Madrid, 1976, pp. 226 y ss.) habla de "omitir por comisión", Silva Sánchez (El delito de omisión. Concepto y sistema. Bosch, Barcelona, 1986, pp. 344 y ss.; «El delito de omisión. Concepto y sistema. Bosch, Barcelona, 1986, pp. 344 y ss.; «La regulación de la "comisión por omisión" ". El nuevo código penal: cinco cuestiones fundamentales, Bosch, Barcelona, 1997, 
El que omite impedir la realización del hecho punible será sancionado:

1. Si tiene el deber jurídico de impedirlo o si crea un peligro inminente que fuera propio para producirlo.

2. Si la omisión corresponde a la realización del tipo mediante un hacer.

La pena del omiso podrá ser atenuada.

Este precepto, al mencionar cuáles son los presupuestos para que una persona responda penalmente a título de omisión viene a concretar, parcialmente, el panorama legal de los delitos omisivos que establece el Art. 110 CP. Parcialmente porque no se refiere a todas las omisiones penalmente relevantes, sino sólo a las impropias que, con las reservas del caso, equipararemos para efectos prácticos a la comisión por omisión (vid. nota 26).

2 La fórmula ex nibilo nibil fit puede tener validez en el campo de las ciencias de la naturaleza más no en terreno jurídico, en donde la imputación de responsabilidad penal por un comportamiento omisivo jurídicamente relevante tiene que responder a criterios normativos. En otras palabras, las omisiones no siempre son ausencia de energía por el contrario, esto sucede las menos de las veces- ya que por lo general la responsabilidad penal nacerá del hecho de haber realizado una acción distinta a la obligada. Se trata de aceptar que las relaciones del hombre con el mundo exterior se pueden producir bien por un

pp. 70 y ss.) cuando propone las "omisiones de gravedad intermedia", que serían omisiones puras generales estructuras sobre consideraciones de solidaridad en aras de las protección de bienes jurídicos individuales y Arán Muñoz Conde/García) (op. cit., p 268) al hablar de delitos de «omisión y resultadon. Jescheck por su parte, postula un cambio terminológico de "propio» e «impropio" por "simple" y "cualificado". ob.cit. p. 551). La equiparación que un sector de la doctrina suele hacer entre los tipos de injusto omisivos puros y de omisión propia, por un lado, y de omisión impropia y comisión por omisión, por otro, no resulta del todo certera en la medida en que los criterios de clasificación son distintos, aunque lo cierto es que la mayoría de las veces la omisión pura estará prevista expresamente por la ley y será, en consecuencia, también omisión propia, mientras que por lo general la comisión por omisión no estará prevista por la ley, pero nada obsta para que siempre sea así. Por ejemplo, el Art. $387 \mathrm{CP}$ in fine que regula el peculado por negligencia es un delito cuya estructura típica responde tanto a la omisión propia (porque está expresamente como funcionario público) da ocasión a que otra persona sustraiga caudales y efectos públicos). 
hacer -se incide en el mundo poniendo en marcha cadenas causalesbien por un no hacer -dejando que las cosas sigan su curso o que permanezcan como estaban-, ${ }^{27}$ siendo del caso que en los delitos omisivos el «proceso causal y su resultado no se imputan jurídicamente al causante, que puede ser un factor natural, o no se imputa jurídicamente sólo al causante (a quien se atribuiría, por supuesto, a título de comisión activa, dados los demás requisitos) sino a quien, sin poner en marcha el curso causal (sin causar), asumió el comportamiento de actuar a modo de barrera de contención del riesgo (del proceso causal), no haciéndolo luegom. ${ }^{28}$

Así, según la literalidad del Art. $13^{\circ} \mathrm{CP}$-y habida cuenta que no existe inclusión alguna entre los dos numerales del mismo- para que se pueda sancionar a alguien por omisión éste tiene que haber omitido impedir la realización del hecho punible (i) a pesar de tener el deber jurídico de impedirlo (el hecho punible); (ii) a pesar de haber creado un peligro inminente que fuera propio para producirlo (el hecho punible); (iii) o cuando su omisión corresponda a la realización del tipo mediante un hacer. Como se aprecia, el común denominador está dado por el encabezado del precepto: haber omitido impedir la realización del hecho punible.

Pues bien, si algo se puede inferir a partir de que alguien «tiene el deber de impedir la realización del hecho punible», es que ese alguien, con un comportamiento activo, es decir, con la puesta en marcha de cursos causales, ha creado un riesgo para un bien jurídico y como tal tiene el deber de evitar que el bien jurídico llegue a lesionarse (supuestos de injerencia o, lo que es lo mismo, los supuestos en que se ha creado un peligro inminente que fuera propio para producir el hecho punible), o que ha asumido la obligación de evitar que el bien jurídico se lesione como consecuencia de comportamientos de terceras personas, esto es, no pone en marcha cursos causales que interrumpan aquellos que se dirigen hacia la lesión del bien jurídico a pesar de estar obligado a hacerlo (supuestos en que se tiene el deber jurídico de impedir el hecho jurídico). ${ }^{29}$

27 E. Gimbernat, «Sobre los conceptos de omisión y comportamiento». ADPCP, (1987III), p. 583 .

28 J.M. Silva Sánchez, “La regulación [...]» op.cit. p. 77.

29 Al respecto, E. Gimbernat, "Causalidad, omisión e imprudencia». ADPCP, (1994- 
Acorde con ello, este apartado abarca supuestos como el de la enfermera que omite suministrar el vital medicamento a su paciente a consecuencia de lo cual éste fallece, o al del salvavidas que omite el rescate del bañista, supuestos de autoría en delito omisivos, pero también aquellos como el de la persona que contempla inerte como un tercero realiza un delito de violación contra la libertad sexual sin impedirlo o dificultarlo o el de la madre que no impide o dificulta los continuos y reiterados malos tratos por parte de su esposo a su menor hijo; supuestos de participación omisiva ${ }^{30}$ en los que se omite impedir o dificultar la realización de un delito.

3 Entre los dos numerales del Art. $13^{\circ} \mathrm{CP}$ no existe signo lingüístico alguno que denote inclusión ni exclusión, ${ }^{31}$ es decir, la ley no dice si se debe tener el deber jurídico de impedir el hecho punible o si se debe haber creado un peligro inminente que fuera propio para producirlo $y$, además, que la omisión corresponde a la realización del tipo mediante un hacer o, si por el contrario, basta con tener el deber jurídico de impedir el hecho punible o con haber creado un peligro inminente que fuera propio para producirlo, o con que la omisión corresponde a la realización del tipo mediante un hacer. Cabe pues el recurso a la naturaleza jurídica de la institución.

Es doctrina unánime reconocer que la persona a la que se pretende imputar, a título de autoría, un delito cometido de manera omisiva,

III), pp. 58 y 59: «[...] únicamente existe una comisión por omisión dolosa cuando el encargado de vigilar un foco de peligro preexistente, mediante la ausencia de una medida de precaución que le incumbe, lo desestabiliza intencionadamente condicionando dicho foco con toda seguridad el resultado típico. [...] La ausencia de una medida de precaución preceptivo ha transformado, en estos casos dolosamente, un foco de peligro de permitido, siendo éste el causante, con toda seguridad, del resultado típicom.

30 Así, G. Portilla Contreras, La participación omisiva en delitos comisivos. Ejemplar dactilografiado de la conferencia impartida en los XX Cursos de verano de la Universidad de Cádiz, San Roque, 1999.

31 Con anterioridad a la reforma del Art. $13.1 \mathrm{CP}$ de 11 de noviembre de 1996 se establecía:

«El que omite impedir la realización del hecho punible será sancionado:

1. Si tiene el deber moral o jurídico de impedirlo o si crea un peligro inminente que fuera propio para producirla; $y$

2. SI la omisión corresponde a la realización del tipo mediante un hacer.

La pena del omiso podrá ser atenuadan.

Como se aprecia, la letra "y» hacía clara alusión a la necesidad de concurrencia de ambos numerales. En todo caso, felizmente, la modificación desterró a la moral como origen de deberes jurídicos. 
debe ostentar determinadas características que permitan exigirle a él, y no al resto de ciudadanos, la evitación del resultado. Se trata, en definitiva, de un deber especial que consiste en garantizar la incolumidad de un bien jurídico penalmente protegido; de ahí que un sector cualificado de la doctrina entienda que los delitos de omisión son delitos que consisten en la infracción de un deber. ${ }^{32}$ Estos deberes son las llamadas posición de deber de garante, y las únicas fuentes de estas posiciones de garante, según nuestro ordenamiento jurídico, son el contrato y la ley (deber jurídico) y la injerencia o actuar precedente (crear un peligro inminente que fuere propio para producir el hecho punible) que se recogen en el Art. $13^{\circ} 1 \mathrm{CP}$.

Así las cosas, no hay base legal para hablar de otras fuentes de deber de garante que no sean aquellas que expresamente se reconocen por la ley. En otras palabras, y sin perjuicio de reconocer que el legislador ha optado por reconocer fuentes formales de deber de garante en vez de fuentes materiales, se deben descartar, por ser analogía in malam partem, el recurso a las fuentes de posición de garante que se fundamentan en el deber de protección de un bien jurídico o en el deber de control de una fuente de peligro que no se encuentren expresamente tipificadas.

$4 \mathrm{La}$ injerencia o actuar precedente apunta a que quien con su conducta pone en peligro un bien jurídico asume la obligación de evitar que éste se lesione. Y no es necesario que la conducta precedente sea ilícita, por el contrario, en la mayoría de ocasiones será lícita como tantas conductas o actividades de riesgo socialmente aceptadas. Acorde con ello, en lo que nos interesa, y habiendo señalado que la actividad empresarial puede ser considerada como una actividad de riesgo (infra III.2) cuya puesta en marcha crea un peligro inminente que es propio para producir resultados lesivos en bienes jurídicos, la actividad empresarial, per se, se subsume en la inferencia o actuar precedente como fuente de deber de garante, algo que se aprecia con claridad en las grandes sociedades mercantiles -y ni que decir de las transnacionales-.

32 Los delitos omisivos, al igual que los delitos especiales, son considerados como delitos consistentes en la infracción de un deber (Pflichtdelikte). Por todos, C. Roxin, Autoria [...] op. cit., pp. 496 y ss. D-M. Luzón Peña. Curso de Derecho penal. Parte General I. Universitas, Madrid, 1998, pp. 305 y 306, aunque «no se puede admitir con carácter general e independiente de la formulación típica la categoría de infracción de un deber (...) solamente habrá delitos de infracción de un deber cuando un tipo configure efectivamente en ese sentido la descripción típica». 
5 Empero, la existencia de un deber que consiste en la evitación de un resultado lesivo no puede sustentar por sí mismo la imposición de una pena, ya que, de ser así, no se podría diferenciar, por ejemplo, entre una infracción civil o mercantil por incumplimiento contractual y un delito cometido por omisión en que se haya hecho caso omiso al deber jurídico de garante que se origina en la ley, un contrato o por actuar precedente.

De esta manera, tiene que realizarse un juicio de equivalencia valorativa entre la omisión realizada y la comisión, tal como está regulado por la ley, de suerte que se pueda afirmar que entre ambas existe una identidad estructural en el plano normativo-material. ${ }^{33}$ Es esto lo que hay que interpretar cuando la ley dice «Si la omisión corresponde a la realización del tipo mediante un hacer", ya que un delito perpetrado en comisión por omisión comparte la misma estructura (normativa, no típica) que el mismo delito cometido de manera comisiva: se trata del mismo delito. Así, el juicio de equivalencia tiene que ser abordado, en primer lugar, sobre la base de las posiciones de garante que, según doctrina que se comparte, encuentra su fundamento en el dominio sobre la causa del resultado y, en segundo lugar, teniendo en cuenta que la posición de garante nada tiene que ver con la posibilidad de evitar el resultado habida cuenta que dicha posibilidad puede recaer también sobre un no garante ${ }^{34}$ (por ejemplo, no sólo el salvavidas puede y está en condiciones de rescatar el ahogado, sino también otros bañistas que tengan noción de primeros auxilios), por lo que cabe individualizar la acción cuya omisión será portadora de lo injusto típico. ${ }^{35} 36$

33 Por rodos, J.M. Silva Sánchez, «La regulación [...]». Op. cit., pp. 66 y ss.

34 Como ha afirmado Gracia Martín («La comisión por omisión en el derecho penal español". Actualidad Penal, (1995-2), pp. 708 y ss.): «...la evitación del resultado es posible a partir de la realización de una pluralidad de acciones que son susceptibles de producir efectos salvadores en diversos estadios del curso causal peligroso. La omisión de una cualquiera de ellas, sin embargo, no da lugar a comisión por omision". Vid, en especial, la bibliografía citada en nota 156.

35 Ibidem. pp. 709 y ss.

36 Según el derecho positivo la pena del omiso puede ser atenuada. No se hace alusión a los criterios en función a los cuales es Juez gradúa los parámetros de dicha atenuación, pero se ha de entender que la atenuación está referida a la pena que hubiera tenido el agente de 


\section{La actividad empresarial como actividad de riesgo}

\section{La concepción de la sociedad en la que cualquier contacto social}

haber cometido el delito de manera comisiva, no a la pena conminada en el delito, por lo que no cabe sobrepasar el mínimo legal.

No puede dejar de llamar la atención sobre esta prerrogativa, en el sentido de ¿qué es lo que justifica que los delitos omisivos puedan ser reprimidos con una pena inferior a los delitos comisivos? Si algo puede justificar la atenuación de la pena es el desvalor de acción y de resultado, la culpabilidad del sujeto o las necesidades de prevención general y especial. Así, la respuesta a la interrogante planteada, si acaso pueda haber una que sea lógica, tiene que ser elaborada, en primer lugar, al margen del bien jurídico toda vez que éste se lesiona por igual en las modalidades omisivas que en las comisivas ( $\mathrm{La}$ muerte es muerte y, por tanto, lesión del bien jurídico vida, tanto si se mata clavando un puñal en la cavidad toráxica de la víctima como si no se suministra los medicamentos que el médico tiene la obligación de suministrar a su paciente). Además, se tiene que tener en cuenta los efectos de prevención general de la pena, lo que equivaldría a decir que los delitos cometidos por omisión generan -según el legislador- un rechazo por parte de la colectividad inferior al que generan los delitos comisivos y, en consecuencia, no está tan interesado, desde una óptica de prevención general, en prevenirlos como a los comisivos, y teniendo en cuenta también los efectos de prevención especial, lo que equivaldría a reconocer que el omiso no tiene las mismas necesidades de resocialización que el delincuente condenado por un delito comisivo. Si bien se precisa más energía para transformar la decisión delictual en un hecho mediante una acción que mediante una omisión, es cierto también que en muchos delitos omisivos el contenido del injusto y la culpabilidad no son menores que en los correspondientes delitos comisivos, por lo que cabría pensar en que la atenuación, en tanto facultativa, una feliz regulación (respecto a esto último, H.H. Jescheck, op. cit., pp. 555 y ss.).

Sin embargo, en nuestro concepto no debería existir ni siquiera la posibilidad facultativa de atenuación de la pena, dado que se parte del presupuesto de una identidad o equivalencia en el plano normativo, valorativo entre la comisión y la omisión, en cuya función el contenido del injusto típico de ambas es idéntico, de suerte que la pena de la primera no tiene porqué ser diferente a la de segunda. Claramente, en ese sentido, L. Gracia Martín, Op. cit., p. 713. Tal vez, el afán de modernidad del legislador le haya hecho incorporar la posibilidad de reducir la pena en estos casos, siguiendo el 12 del Proyecto Alternativo Alemán de 1966 y el 13 del Código Penal de Alemania Occidental de 1975 (Según la Exposición de Motivos del Código Penal de 1991, esos son los antecedentes legislativos que la Comisión Revisora nacional utilizó para «subsanar un importante vacío legislativo al señalar los requisitos para que la comisión por omisión pueda llegar ser castigada". Vid. Exposición de Motivos del Código Penal de 1991, apartado sobre el Hecho Punible, Bases de la Punibilidad), pero lo cierto es que -sin perjuicio de hacer estudios de derecho comparado- más vale analizar la realidad nacional del país para el que se legisla, realidad que obedece a experiencias particulares cuya historia recoge y legislar en función a ello, que importar ciegamente preceptos que responde a una historia jurídica distinta, experiencias ajenas y coyunturas sociales de otros países que, por más avanzados que sean, no justifican la incorporación de preceptos que luego aparecen como disfuncionales frente al íntegro de nuestro Sistema jurídico-penal (Sobre las razones que llevaron al legislador alemán a incorporar la posibilidad de atenuar la pena al omiso, Vid. J.M. Silva Sánchez, "La regulación [...]». Op. cit., pp. 53 y ss.). 
entraña un riesgo -incluso cuando se actúa de buena fe ${ }^{37}$ constituye, sin duda, un punto de partida en cuya función se puede entender lo que en la actualidad se califica como "riesgo permitido". Como quiera que una sociedad sin riesgos no es posible o, mejor dicho, nadie se plantea renunciar seriamente a una sociedad así configurada -por los beneficios que representa-, no es factible una normativa que excluya la total ausencia de riesgos, de donde se deduce que los riesgos inherentes de la configuración social han de ser tolerados en calidad de riesgos permitidos. ${ }^{38}$ Así, al amparo de esta genérica concepción habría que reconocer que todas las relaciones interpersonales -es decir, todos los comportamientos que potencialmente puedan influir en terceras personas: todos los comportamientos activos u omisivos- pueden ser calificados de actividades de riesgo, pero no ofrece criterio alguno que permita acotar del universo que componen los riesgos permitidos de los prohibidos. En todo caso, la sociedad actual es una «sociedad de riesgos» que se caracteriza por la constante utilización de instrumentos técnicos y el recurso a procedimientos per se peligrosos.

2 Para lo que nos interesa, la actividad empresarial puede ser analizada desde un plano dual, en donde una cara de la moneda está constituida por los beneficios (ahorro de tiempo, disminución de costos) y confort que representan estos avances para la humanidad. Y la otra cara la constituyen los riesgos implícitos de estos avances técnicos, referidos a daños no conmensurables que afectan a todos los miembros de la colectividad por igual. ${ }^{39}$

37 G. Jakobs, La imputación objetiva en Derecho penal. Trad. Cancio Maliá. Civitas, Madrid, 1996, p. 117: "a través de un apretón de manos, a pesar de todas las precauciones, una infección; en el tráfico rodado pucde producirse un accidente que, al menos mientras exista tráfico, sea inevitable; un alimento que alguien ha servido puede estar en mal estado sin que sea posible percatarse de ello; una anestesia médicamente indicada, y aplicada conforme a la lex artis, puede provocar una lesión [...]".

38 Ibidem, p. 118.

39 La "sociedad de riesgos" o "sociedad del riesgo" (Risikogesellschaft) es propia de sociedades postindustriales. Cfr. J.M. Silva Sánchez, La expansión [...] op. cit., pp. 21-24. Resulta gráficas las palabras de este autor (pp. 21 y 22): "En efecto, la sociedad actual aparece caracterizada, de un lado, por la aparición de avances tecnológicos sin parangón en toda la historia de la humanidad. El extraordinario desarrollo de la técnica de avances tecnológicos sin parangón en toda la historia de la humanidad. El extraordinario desarrollo de la técnica ha tenido y sigue teniendo, obviamente, repercusiones directas en un incremento del bienestar individual. Sin embargo, conviene no ignorar sus consecuencias negativas. De entre ellas, la que aquí interesa resaltar es la configuración del riesgo de procedencia humana como 
Este planteamiento conlleva la aceptación de que la actividad empresarial, independientemente del giro o rama industrial que desarrolle, es, hoy por hoy, una actividad de riesgo, toda vez que «[...] en cuanto tarea productiva o distributiva que requiere aplicación de energía al mundo exterior para proceder a su transformación, supone, en mayor o menor medida, la generación de riesgos para bienes jurídicos ajenos. La razón por la que la sociedad permite y fomenta la referida actividad, incluso en supuestos en que desata graves peligros para bienes fundamentales, radica tanto en su utilidad general como en la perspectiva de interposición de los adecuados medios de control del riesgo por parte de sus agentes». ${ }^{40}$

3 El deber de aseguramiento en virtud de responsabilidades de organización o la responsabilidad por el ejercicio de facultades individuales de autoorganización

1 La existencia de un deber del titular de la empresa en cuya virtud tenga que "evitar" la comisión de hechos antijurídicos en el seno de la empresa que dirige y que se manifiestan, bien para el exterior, bien para el interior de la misma, no se cuestiona ni se pone en tela de juicio, habida cuenta que resulta lógico que aquellas personas que ponen en marcha procesos causales en mérito a los cuales se organiza y desarrolla una actividad de riesgo socialmente aceptado (e incluso, según un sector de la doctrina, una actividad que no represente a priori riesgo alguno), tengan que responder por los daños que en el desarrollo de dicha actividad se generen. En todo caso, lo que se discute es el fundamento, los límites de dicho deber y la manera como éste se puede ejercer. $^{41}$

fenómeno social estructural. En otras palabras, el hecho de que buena parte de las amenazas a que los ciudadanos estamos expuestos provengan precisamente de decisiones que otros conciudadanos en el manejo de los avances técnicos: riesgos para el medio ambiente o para los consumidores o usuarios que derivan de las aplicaciones técnicas de los desarrollos en la biología, la genética, a energía nuclear, la informática, las comunicaciones, etcérera».

40 J.A. Lascuraín, Op. cit., p. 216, E. Bacigalupo, "La posición [...]». op. cit., p. 63: "Ja empresa mercantil es generadora de diversos peligros, provenientes de distintas fuentes de riesgos, que, afectan, a su vez, a bienes jurídicos diferentes» y C. Martínez-Buján,. Ob.cit. pp. 191 y ss.

41 Así, W. Frisch. "Problemas fundamentales de la responsabilidad penal de los órganos de dirección de la empresa. Responsabilidad penal en el ámbito de al responsabilidad de la cmpresa $y$ de al división del trabajom. Responsabilidad Penal de las Empresas y sus Organos y Responsabilidad por el Producto, Luzón/Mir Puig, ed.), Bosch, Barcelona, 1996, p. 111, J.A. 
La idea de la autoorganización y las facultades y deberes que de ella se derivan, brinda un primer fundamento para la imputación de comportamiento ilícitos. Derivada del principio de libertad y del derecho al desarrollo de la personalidad, se entiende que la actividad de los seres humanos no conoce más limite que los derivados del correlativo derecho de los demás ciudadanos. ${ }^{42}$ Acorde con ello, la responsabilidad en el ámbito de la organización encuentra su fundamento en el deber -que se deriva de una pacífica convivencia en sociedad- de asegurar que los cursos peligrosos desplegados por cada quien en su propia actividad no importen lesiones a bienes jurídicos de éstos. ${ }^{43}$ Es lo que se conoce como «deber de aseguramiento en virtud de responsabilidad por organización». ${ }^{44}$ Trasladado al ámbito que nos interesa esto quiere decir que, sobre la base de la autoorganización, en el ámbito empresarial se puede fundamentar la existencia de un derecho y deber que le corresponde al titular -que a estos efectos será aquel que configura y organiza la actividad con exclusión de terceros- en cuya virtud asume las consecuencias de dicha organización, sean positivos (tiene el derecho de hacerse con los beneficios que produce la actividad) como negativas (tiene el deber de responder por las lesiones para bienes jurídicos protegidos). Acorde con esto, se encuentra obligado a controlar que las conductas que se realizan en el ámbito negocial que él ha

Lascuraín, op. cit., pp. 211 y ss., H. Achenbach, Op. cit., p. 386. Por su parte, W. Bottke, "Responsabilidad por la no evitación de hechos punibles de subordinados en la empresa económica". Responsabilidad penal de las Empresas y sus Organos y Responsabilidad por el Producto, (Luzón/Mir Puig, ed), Bosch, Barcelona, 1996, p. 146 sostiene que la fundamentación y los límites no es cuestión difícil.

42 G. Jakobs, Derecho penal. Parte general. Fundamentos y teoría de la imputación. (Trad. Cuello Contreras y Serrano González de Murillo), Marcial Pons, Madrid, 1995, 7/56: «El fundamento de la responsabilidad en los supuestos básicos de los delitos de omisión es que el autor, por ser causante, amplía su ámbito de organización sin consideración a otras personas y a costa de éstas» y J.A. Lascurain, op. cit., p. 211.

43 G. Jacobs, Derecho Penal ... Op. cit., 29/29: “Este ámbito de organización puede definirse, además de a través de acciones -la responsabilidad por acción es responsabilidad por la vulneración del aseguramiento, en la relación, del aparato psícofísico- a través de medios materiales de despliegue; ello conduce a los deberes de relación, es decir a los deberes de asegurar frente a peligros derivados de objetos o actividades empresariales".

44 G. Jakobs, Derecho penal ... op. cit., 29/29, 29/30, 29/31. En el mismo sentido, W. Frisch, Op. cit., p. 117, J.M. Silva Sánchez, "Responsabilidad...». op. cit., pF. 376 y ss. y Ma.P. Batista, Op. cit., p. 87. 
configurado (tanto omisivas como comisivas ${ }^{45}$ ) no generen resultados lesivos para bienes jurídicos protegidos. ${ }^{46}$

2 A pesar de ciertas circunstancias "particulares" propias de la actividad empresarial, la posición de garante en el ámbito empresarial no puede fundamentarse ni concretarse dejando de lado la naturaleza del género al cual pertenece. En otras palabras, la doctrina sobre la comisión por omisión en la criminalidad empresarial no puede ser abordada de manera diferente a la teoría general de la comisión por omisión $^{47}$ propia de la Parte General.

\section{El «dominio» sobre la causa del resultado}

1 En los comportamientos omisivos el sujeto tiene que haber tenido la capacidad y posibilidad psico-física de realizar la conducta prescrita, caso contrario, se sostiene unánimemente ${ }^{48}$ que no ha tenido la capacidad de evitar el resultado por lo que se niega la tipicidad del comportamiento. ${ }^{49}$ En cierto modo, se trata de una delimitación del círculo de poten-

45 G. Jakobs, Derecho penal [...] op. cit., 7/56: «el fundamento de la responsabilidad en los supuestos básicos de los delitos de comisión es que el autor, por ser causante, amplía su ámbito de organización sin consideración a otras personas y a costa de éstas», W. Frisch, $O p$. cit., pp. 100, 101 y 113, para quien el fundamento normativo de la posición de garante estriba en la ponderación de intereses que se deriva del principio de organización, y de la exclusión de terceros en las conductas que uno emprende y que suponen un riesgo para otros.

46 J.A. Lascuraín, $O p$. cit., pp. 210 y ss., con matices: U.K. Kindhauser, "Acerca de la legitimidad de los delitos de peligro abstracto en el ámbito del derecho penal económico». En: Hacia un Derecho Penal Económico Europeo. (Jornadas en Homenaje al Prof. Tiedemann). Madrid. 1995, p. 442 y sobre todo 450, W. Frisch, Op. cit., p. 112, W. Bottke, Op. cit., p.145, C. Martínez-Buján, Op. cit., p. 206, J.M. Silva Sánchez, "Responsabilidad [...]».op. cit., p.371, en especial, nota 47.

47 J.M. Silva Sánchez, . «Responsabilidad [...]». op. cit., p. 374, W. Bottke, op. cit., pp. 137 y ss., quien sostiene que hay que recurrir a la teoría de la omisión y de la autoría y participación. Implícitamente, H. Achenbach, ob.cit. p.397 cuando sostiene que no hay unanimidad ni en la fundamentación ni en los límites de los deberes de garante del empresario, ya que no hay unanimidad en la dogmática de los delitos de omisión) y, en consecuencia, no se puede recurrir a preceptos específicos para fundamentar la naturaleza del deber de garante del empresario B. Schünemann, "Cuestiones [...]". op. cit., p. 533 y 534.

48 Por todos, J.M. Silva Sánchez, El delito de omisión, concepto y sistema. Bosch, Barcelona, 1986, pp. 26 y ss. E. Bacigalupo, Los delitos impropios de omisión. Panedille, Buenos Aires, 1970, pp. 124 y ss.

49 Quintero/Morales/Prats, Op. cit.,p. 375: «La imputación descansará en un razonamiento normativo, al que se le dotará de elementos que permitan establecer esa equiparación, como es principalmente, y al margen del dolo, el dominio o control sobre la producción del resultado", E. Bacigalupo, Principios [...] op. cit., p. 260. 
ciales autores. Empero, esta capacidad no debe confundirse con el «dominio" que fundamenta la posición de garante, ya que la posibilidad de evitar el resultado no es monopolio de quienes ostentan una posición de garante sino, incluso, de otras personas (supra nota 34).

Así las cosas, si tenemos en cuenta lo anteriormente mencionado, podemos concluir que el titular de la empresa está obligado a garantizar, cuando pueda hacerlo, que las conductas que se realizan en su ámbito de organización no lesionen intereses ajenos. Sin embargo, en nuestro concepto, no se trata únicamente de responder por aquellos resultados que desde la posición de titular que se ostente se puedan evitar sino, incluso, de responder por aquellos otros que no se puede evitar pero que, ello no obstante, desde la posición de titular que se ostenta, son exigibles que se hubieran podido controlar: se trata de una responsabilidad que se fundamente no sólo en el no evitar a pesar de poder, sino en el no alcanzar y/o mantener un estado de competencia -cuando éste se pueda exigir- en cuya virtud se hubiera podido estar en condiciones de evitar. ${ }^{50}$

2 El dominio propio del garante surge, en palabras de Schünemann, del dominio de la persona (en este caso del empresario) sobre la causa del resultado. ${ }^{51}$ Se trata, por un lado, de un dominio fáctico sobre los elementos y procedimientos peligrosos del establecimiento y, por otro, de un dominio sobre los trabajadores. ${ }^{52}$

Respecto al dominio sobre las cosas y procedimientos, y teniendo en cuenta la división del trabajo en el ámbito empresarial, cada cotitular de la custodia será responsable según su parte de dominio, ${ }^{53}$ además, los que se encuentren más cerca de la cosa tienen que realizar actividades materiales relativas a su competencia en el establecimiento que están indicadas para el control de la fuente de peligro (deberes primarios de garante); los superiores jerárquicos que son cotitulares de la custodia se encuentran obligados a la coordinación y al control (deberes secundarios de garante). ${ }^{54} \mathrm{El}$ dominio de las personas que puede

50 En el mismo sentido, J.A. Lascuraín, op. cit., p. 216.

51 "Cuestiones [...]". op. cit., p. 536.

52 Ibidem, p.535. En un sentido similar W. Bottke, op.cit.,p. 147, J.M. Silva Sánchez, “Responsabilidad ...».op. cit., p.371 C. Martínez-Buján, op. cit., p. 196 y ss.

53 B. Schünemann, "Cuestiones [...]».op. cit., p. 537.

54 B. Schünemann, "Cuestiones [...]». op. cit.,p. 538. En sentido similar, J.M. Silva 
fundamentar también el deber de garante, se basa en el poder de mando $y$, sobre todo, en la información del superior. ${ }^{55}$

Bottke ha sostenido que el fundamento del deber de garante del empresario no puede ser la posibilidad fáctica de evitar el resultado (posibilidad fáctica que se aplica a los elementos y procedimientos peligrosos, más no hacia los subordinados), toda vez que esta capacidad fáctica no es monopolio de los titulares sino que puede ostentarla también gente que se sitúa en el mismo escalafón que el subordinado. ${ }^{56}$ En nuestro concepto, si se tiene en cuenta lo dicho sobre los deberes de aseguramiento que se derivan de la autoorganización con exclusión de terceros, se puede sostener coherentemente que, si bien no sólo los titulares tienen una capacidad fáctica de evitar los resultados lesivos en la gestión empresarial, sólo éstos están llamados a hacerlo, habida cuenta que ellos, y no el resto, son quienes se organizan y dirigen la actividad.

De este modo, ambas formas de responsabilidad de garante de los órganos de dirección de la empresa por los hechos punibles cometidos por elementos subordinados (sobre los elementos y procedimiento y sobre las personas) significan una división de la responsabilidad penal aplicable a la práctica. «El alcance de estos tipos de responsabilidad es con ello diferente hasta el punto que el dominio material es, en efecto, "permanente ante el exceso" (excessfest), porque una pérdida de la custodia de la cosa contraria al cuidado fundamenta la imputación de las consecuencias derivadas de la misma; pero no es "permanente ante la descentralización" (dezentralisierungsfest), porque la misma posición más alta en la jerarquía de la empresa no da lugar a una responsabilidad de garantía sin que exista un dominio inmediato sobre la cosa, facilitado con tal motivo, al menos en forma de custodia. Con el dominio personal sucede justamente lo contrario, porque ciertamente

Sánchez, «Responsabilidad [...]». Op. cit.,p. 371: «la estructura jerárquica y de división del trabajo genera unos ámbitos de competencia individual De cada uno de estos ámbitos de competencia -situados a diferente nivel- se hace responsable un sujeto, quien, de ese modo, pasa a responder del output que surja de la correspondiente esfera de dominio, cuya organización interna le compete».

55 B. Chünemann, "Cuestiones [...]».op. cit.,p. 539.

56 W. Bottke, op.cit. pp. 142-146. Según este autor, el fundamento material está dado por la equitativa compensación social de los efectos internos y externos de la organización de un círculo vital específico que fundamenta el poder en un elevado grado. 
no es "permanente ante el exceso" (los hechos de los subordinados en su propio interés caen desde el principio fuera de su dominio del grupo), pero sí "permanente ante la descentralización», porque sólo en el escalón más alto de la jerarquía, o sea, en la dirección de la empresa, se solapan el poder legal de mando y los diferentes canales de información, de modo que aquí -al menos desde un punto de vista teórico- se encuentra incluso la forma más intensa de dominio»." ${ }^{57}$

3 En resumen, el deber de garante del titular se fundamenta en el hecho de haber organizado y puesto en marcha, libremente y con exclusión de terceros, una actividad empresarial (que, per se, conlleva riesgos) que implica el recurso y utilización, por un lado, de elementos y procedimientos peligrosos y, por otro, de personal bajo su dirección, siendo el caso que al tener un dominio sobre éstos como algo derivado de la estructura organizativa, tiene también, en consecuencia, el deber de evitar que los mismos lesionen intereses de terceros en su utilización y puesta en marcha (elementos y procedimientos, respectivamente) o comportamientos (personal subordinado) para la empresa. Con todo, el problema radica -como ha señalado Martínez-Buján- en conjugar estos dos criterios y precisar cuándo aparece y, sobre todo, cuáles son, concretamente, los deberes de garante del titular que surgen de la conexión entre las facultades de autoorganización y la actuación del subordinado..$^{58}$

\section{5 ¿Causalidad hipotética o incremento del riesgo?}

1 En el ámbito de los delitos omisivos la relación de causalidad ha sido reemplazada por una causalidad hipotética, con arreglo a la cual una omisión será causa de un resultado si, de haberse realizado la acción, el resultado desaparece con una probabilidad cercana a la certeza; sin embargo, está claro que en las omisiones no cabe hablar de una causalidad en sentido material que nunca dejará de ser una presunción desfavorable al reo al no poder comprobarse, sino sólo de una causalidad en sentido jurídico, en cuya virtud se pueda atribuir a alguien el pro- 
ceso de producción del resultado. ${ }^{59}$ Así, si para los delitos comisivos se exige la seguridad de que el comportamiento haya causado el resultado, ya resulta dudoso que para los delitos omisivos se flexibilicen los baremos de seguridad y se exija, solamente, una probabilidad rayana a la certeza, sin contar que si en el plano teórico se exige una probabilidad rayana a la certeza, se permite en el práctico que el deseo de los jueces de no dejar impunes determinados comportamiento omisivos o de sancionar como autor en comisión por omisión a quien en realidad es cómplice accesorio en comisión por omisión (y como tal merecen una inferior)- tenga un aval legal, habida cuenta que los criterios para determinar los límites de lo que es probable y lo que no lo es -y, en consecuencia, también los límites- nadie los conoce con precisión, siendo que ofrece poco o nada de concreción.

Además, la exigencia de una causalidad hipotética (o cuasi-causalidad) en el ámbito empresarial, amén de la confluencia de cursos causales en virtud de la división del trabajo y el respeto al principio de jerarquía, podría generar que a pesar de haberse cumplido adecuadamente con los deberes de control apareciera el resultado lesivo. ${ }^{60}$

2 Así, Gimbernat ha manifestado que la cuasicausalidad en los delitos de comisión por omisión no puede consistir en la hipótesis -más o menos probable- de que la acción omitida hubiera evitado el resultado, sino que hay que exigir la seguridad de que, como consecuencia de la desestabilización, por inactividad, de un foco de peligro, éste haya desembocado con seguridad (aspecto objetivo) e intencional o imprudentemente (aspecto subjetivo) en un resultado típico. ${ }^{61}$ Este planteamiento ofrece la ventaja de estructurarse sobre criterios estrictos, como la seguridad de haber condicionado el resultado típico, es decir, se condice un «derecho penal democrático que -por muy fundadas que sean- rechaza que se opere con sospechas y exige la seguridad y certe-

59 E. Gimbernat, «Causalidad [...]».op. cit.,p. 541. En el mismo sentido, C. MartinezBuján, op. cit., p. 55.

60 B. Schünemann, "Cuestiones [...]». op. cit., p.541. En el mismo sentido, C. Martínez-Buján, Op. cit., p. 209: «en la hipótesis más extremas de déficit de organización no se podría excluir a priori que las concreta lesión del bien jurídico protegido podría haber acontecido igualmente de la misma manera aun cuando se hubiesen cumplido adecuadamente los deberes de control y vigilancia».

61 "Causalidad [...]". op. cit., p. 57 y ss. 
zan. ${ }^{62}$ En sentido parecido se manifiesta Jescheck, cuando afirma que "las conclusiones de la teoría de la condición son aquí menos fiables que en el hacer positivon. ${ }^{63}$

Así las cosas, en la actualidad se prefiere recurrir a la teoría de la imputación objetiva para imputar un resultado a un comportamiento omisivo, ${ }^{64}$ de suerte que además de la posición de garante que ostenta el autor, el riesgo creado tiene que haberse realizado efectivamente en el resultado. De esta manera, Mir Puig afirma que este juicio cabe afirmarlo en caso se compruebe ex post que el resultado se habría evitado (al menos con práctica seguridad) mediante la intervención omitida. ${ }^{65}$

Del mismo modo, se ha sostenido que la imputación objetiva del resultado en los delitos omisivos debe corresponderse, previa comprobación de identidad valorativa en términos normativos entre comportamiento omitido y comportamiento comisivo típico, con un incremento del riesgo. De esta manera, Schünemann, ha propuesto el reemplazo de la causalidad hipotética por una fórmula en función a la cual: «si el resultado se produce mediante una actuación para una empresa ajustada a las instrucciones o con un objeto peligroso del patrimonio de la misa, se aplicará también el parágrafo $13.1 \mathrm{StGB}^{66}$ (o bien el $\$ 8.1 \mathrm{OWiG}^{67}$ ) a los sujetos autorizados para dictar aquellas instrucciones, siempre que los debidos controles hubieran dificultado considerablemente el hecho". ${ }^{68}$

62 Ibidem, p. 27.

63 H.H. Jescheck, op. cit., p. 564.

64 Ibidem.

65 Op. cit., $12 / 78$ y $12 / 81$.

66 Cláusula de la comisión por omisión del Código Penal Alemán:

«1. El que omite un resultado que pertenece al tipo de una ley penal, será punible según esta ley sólo si tenía que responder jurídicamente de que el resultado no se produjera y la omisión corresponde a la realización del tipo por un hacer.

2. La pena puede ser atenuada conforme a lo dispuesto en el $\$ 49$, párr.1".

67 El $\$ 8.1$ de la Ley de Contravenciones Administrativas Alemana (OWiG) es similar al $\$ 13.1 \mathrm{StBG}$, con la salvedad de que se refiere a "precepto que sancione con multa" y a "comisión de un ilícito administrativo" en vez de ley penal y punibilidad, respectivamente.

68 B. Schünemann, "Cuestiones [...]". op. cit., p 541. En el mismo sentido, W. Bottke, op.cit., p. 131 y J.A. Lascuraín, op.cit., p. 216 y C. Martínez-Buján, op. cit., p. 209. 


\section{Contenido del deber objetivo de garante del empresario}

1 La determinación del contenido del deber de garante del empresario, esto es, los deberes en concreto que tiene el titular de la empresa, al igual que para el caso de los delitos imprudentes, tiene que hacerse a la luz de la normativa reguladora de la particular actividad empresarial que se trate, que siempre habrá de tener en cuenta criterios como la importancia del bien jurídico, recognoscibilidad del riesgo y posibilidad de actuación. ${ }^{69}$ Pero dichas normas -que pueden regular tanto de deberes del empresario que se verifican al interior de la empresa (por ejemplo, prevención de riesgos laborales), como a extramuros de la empresa (por ejemplo, la normativa que regula la adecuada publicidad de las instrucciones de uso del producto o de los elementos o materia prima del producto o del proceso de producción del mismo) sólo ofrecen un indicio, habida cuenta que todo deber objetivo de cuidado no puede precisarse al margen de las especificidades que rodean al comportamiento analizado, las mismas que permiten calificarlo, en unas determinadas coordenadas espaciales y temporales, de socialmente adecuado. En caso de que la actividad no se halle sometida a una regulación expresa cabe recurrir a los criterios de «razonabilidad", "prudencia», "diligencia» que, no obstante, debido a su vaguedad y libre interpretación, no ofrecen criterios muy precisos de imputación. ${ }^{70}$

2 En este orden de ideas, cabe precisar que los deberes de garante vinculan al empresario, en el sentido de que debe evitar aquellos comportamientos que a primera vista aparezcan como «demasiados peligrosos" y, con ello, sean no tolerados socialmente, o lo que es lo mismo, sólo cabe que inicie o permita que inicien en su ámbito de dominio cursos causales que, aunque sean portadores de riesgos, sean éstos tolerados. Con todo, no sólo tiene la obligación de controlar y vigilar dichos cursos (los a priori peligrosos) sino que debe evitar que surjan riesgos a posteriori y, en caso surjan, controlarlos y evitar que generen lesiones a bienes jurídicos. ${ }^{71}$ Así, no sólo se deberá imputar aquellos resultados lesivos que sean consecuencia de los riesgos existentes al

69 J.A. Lascuraín, op. cit., p. 216 y C. Martínez-Buján, op. cit., p.207.

70 Loc. cit.

71 W. Frisch, op. cit., p. 116 y ss. 
momento de iniciar la actividad empresarial, sino que habrá que imputar también aquellos resultados que surgen en el desarrollo de la actividad empresarial que, aun cuando no se tenga la capacidad de evitarlos, sea exigible al empresario la ostentación de una capacidad para hacerlo: se trata de una responsabilidad que se fundamenta, como se dijo anteriormente, no sólo en el no evitar pudiendo hacerlo, sino no evitar aun cuando no se puede, pero es exigible, debido a los deberes de aseguramiento que surgen a costa de la organización con exclusión de terceros que efectúa el empresario, que se hubiera podido.

V Formas de ejercer el deber de garante del empresario: especial referencia a la delegación

1 La delegación de actividades mecánicas y deberes de vigilancia no sólo es posible en teoría, sino que es requisito sine quan non en la práctica para poder emprender con éxito cualquier actividad de naturaleza empresarial. Por ello, se ha llegado a afirmar que "no es humanamente posible que quienes deben ejercer una posición de garante, que requiere, por su naturaleza, una distribución de funciones, puedan realizar personalmente todas las operaciones necesarias para el cumplimiento del deberm. ${ }^{72}$ Acorde con ello, en mérito a la delegación, cada uno de los miembros de la empresa se encarga de una parte sin la cual el todo no sería posible, de manera que cada uno individualmente considerado no puede ser responsable (garante) del todo, siendo del caso, en consecuencia, que la responsabilidad penal se incrementará en tanto se escale por la pirámide jerárquica empresarial.

La delegación, para generar efectos en materia penal (poder afirmar que el delegado asume una nueva posición de garante) tiene que ser formal, pero sobre todo, materialmente completa; en otras palabras, no basta el formal nombramiento o encargo o delegación de funciones por parte de un órgano de dirección de la empresa a un subordinado, sino que el acto de delegación tiene que ir acompañado, por un lado, de determinada cuota de libertad (dominio) al delegado 
y, por otro lado, de los medios y recursos técnicos y humanos que le permitan al delegado ejercer en su nuevo ámbito de autoorganización (que como tal genera deberes de aseguramiento) una nueva posición de garante que, llegado el momento, pueda fundamentar responsabilidad penal en comisión por omisión. ${ }^{73}$

2 La delegación, respecto al delegante, ofrece dos ámbitos de estudio. En primer lugar, tiene que seleccionar adecuadamente a las personas sobre quienes delega las funciones. A este respecto se aprecia una responsabilidad in eligiendo en tanto que el titular descargue sus deberes en personas manifiestamente incapaces, faltos de experiencia, pericia o escasos de recursos técnicos que el cumplimiento de la función delegada importa. ${ }^{74}$

En segundo lugar, ‘acaso la delegación a una persona idónea exonera al delegante de responsabilidad penal por los hechos que éste pueda cometer? $\mathrm{O}$, en otras palabras, ‘acaso la delegación libera al delegante de su original posición de garante residual? En definitiva, la delegación de funciones no impide apreciar que la posición de garante originaria no se extingue ni permanece inalterada, sino que se modifica: sobrevive en el delegante una competencia con arreglo a la cual debe supervisar que el delegado cumpla con lo que se le ha encomendado, y si no es así, a corregirlo o cambiarlo. ${ }^{75}$ Culpa in vigilando que le obliga a salvaguardar el carácter no lesivo de las funciones delegadas y le impone el deber de vigilar que el subordinado cumpla con lo que

73 J.A: Lascuraín, op. cit., p. 219, C. Martínez-Buján, op. cit., p. 208, W. Frisch, op. cit., p. 121. J.M. Silva Sánchez, «Criterios [...]». op. cit., p. 20: «Al delegado le incumbe simplemente apercibir de la ausencia de medios y, en tanto ello no se subsana, cumplir con su deber: hacer frente al riesgo asumido con los medios existentes. Aunque no cabe duda de que el tema merece discusión, en el caso de que la producción del resultado se produjera por ausencia de medios, este punto de vista haría responsable sólo al delegante. Incluso aunque el delegado hubiera causado de modo previsible el resultadom.

74 En definitiva, la responsabilidad por culpa in eligendo se origina pro la designación de personas idóneas para el desempeño de la función: que no tengan un determinado nivel de conocimientos acerca de los procesos productivos propios del giro empresarial, que no tengan una capacidad que pueda ser aprobada ex-ante, que no sean expertos, peritos, hábiles, hombres de confianza, etc. Aunque lo cierto es que en este ámbito no habrá muchos problemas habida cuenta que el buen funcionamiento de la empresa dependerá, en definitiva, de la elección del personal.

75 W. Frisch, op. cit., p. 121.

76 Como ha afirmado certeramente W. Frisch, op. cit., p. 116 y 117: «El deber especial que tiene el órgano directivo de realizar sus propias actividades sin lesionar bienes jurídicos 
se le delegó. ${ }^{76}$

No obstante, no hay que olvidar que los conceptos de culpa in vigilando e in eligendo son propios del derecho mercantil, por lo que el recurso a aquellos no puede hacerse sin perder de vista las diferencias que existen entre el derecho mercantil y el derecho penal, toda vez que no es posible aplicar los mismos criterios para fundamentar responsabilidades eminentemente distintas, ${ }^{77}$ por lo que hay que estar a las expectativas que despierta el titular, dadas sus funciones y roles en el tráfico jurídico, en torno a su actuación de control sobre los comportamientos de sus subordinados. De manera tal que se debe poder afirmar que el incumplimiento de este deber de vigilancia es una auténtica fuente de riesgo. ${ }^{78}$

Ahora bien, los criterios en función a los cuales se gradúe el «deber de garante residual» -que consiste en supervisar- tienen que evitar que por exceso la delegación se convierta en un mero dominio mediato y que, por defecto, quede prácticamente eliminada la posición de garantía del delegante. ${ }^{79}$ De manera tal que la precisión de estos criterios habrá de hacerse con atención al tipo de actividad que se trate y a las características de la persona encargada de llevar a cabo la tarea delega$\mathrm{da}$, de suerte que "cuanto mayor sea el riesgo que se pretende controlar y más difícil su control, más intensa habrá de ser la supervisión del delegante. La cualificación y la experiencia del delegado y el tipo de vigencia de una concreta delegación juegan, por el contrario, a favor de una mayor confianza del que delega, que podrá relajar así su actividad de vigilancia. ${ }^{80}$

y eliminando cualquier riesgo cognoscible que pueda existir no finaliza con la delegación de la tarea, sino que en tales casos se convierte en un deber de preocuparse (a través de aquellas medidas organizativas, controles, e intervenciones que sean necesarios) de que dicha delegación no acaba produciendo lesiones de bienes jurídicos". Así también, V.Militello, op. cit., p. 423, al comentar las pautas aceptadas pacíficamente por la doctrina y la jurisprudencia para afirmar la delegación, sostiene que ésta puede ser eximente de responsabilidad, tiene que ser un encargo formalmente constituido y el delegante debe vigilar que el delegado cumpla.

77 L. Zúñiga, "Criminalidad de empresa, criminalidad organizada y modelos e imputación penal» Delincuencia organizada. Aspectos penales, procesales y criminológicos. Ferrél Anarte, edrs.), Servicio de publicaciones de la Universidad de Huelva, Huelva, 1999, p. 220.

78 Ibidem. p. 221.

79 Así, J.A. Lascuraín, op. cit., p. 222 y C. Martínez-Buján, op. cit., p. 203.

80 J.A. Lascuraín, op. cit.,p. 222. 
VI Excurso: El deber de vigilancia como delito de omisión propia (y de omisión pura)

$1 \mathrm{El} \$ 130$ OWiG ha venido a establecer, para el derecho alemán, un deber de vigilancia, con arreglo al cual «el que como titular de un establecimiento o de una empresa omita dolosa o imprudentemente las medidas de vigilancia que se exigen para impedir en el establecimiento o en la empresa las contravenciones contra los deberes que corresponden al titular como tal, y cuya lesión esté amenazada con pena o con multa, comete un ilícito administrativo si se comete una contravención tal que habría podido ser evitada por medio de la pertinente vigilancia. A las medidas de vigilancia exigidas pertenecen también la dirección, la elección cuidadosa y la supervisión de los vigilantes".

Se trata, en definitiva, una norma administrativa que consiste, en primer lugar, en la ejecución de una conducta que constituye delito o infracción administrativa que ha sido realizada en el seno de una empresa por un operario de la misma, y que es contraria a los deberes que incumben al titular de la empresa como tal; en segundo lugar, el titular tiene que haber omitido, a título de dolo o negligencia, las medidas de control necesarias para impedir la infracción; y, en tercer lugar, tiene que acreditarse que la conducta antijurídica del operario habría podido ser evitada mediante la puesta en marcha de las medidas de control adecuadas. La imputación de esta responsabilidad (por infracción a los deberes de vigilancia) se verifica con independencia de la responsabilidad en la que pueda incurrir el órgano de dirección a título de comisión por omisión por el hecho ejecutado materialmente por el subordinado. ${ }^{81}$

2 La doctrina especializada ha formulado fuertes críticas contra esta regulación, tanto desde una perspectiva dogmática cuanto políticocriminal. ${ }^{82}{ }^{82 *}$ En concreto, se le critica vulnerar el principio de deter-

81 Vid. C. Martínez-Buján, op. cit.p. 210 y 211.

82 Vid. B. Schünemann, "Cuestiones..." op. cit.,p. 547 y ss., H. Achenbach, Op. cit., p. 386 y ss., W. Frisch, ob.cit. p. 122 y ss. y C. Martínez-Buján, op. cit., p. 210 y ss.

$82^{\text {a }}$ Se ha manifestado también (B. Schünemann, "Cuestiones [...]».op. cit., p. 548) que el $\$ 130$ OWiG tiene que fracasar necesariamente ante la moderna división del trabajo y la descentralización en la empresa, "ya que los órganos de control instituidos por el propio 
minación al no establecer cuáles son las medidas de vigilancia cuya inobservancia genera responsabilidad; se afirma que constituye una condición objetiva de sanción -el equivalente administrativo de las condiciones objetivas de punibilidad ${ }^{83}$ - al no exigirse vínculo alguno entre la ausencia de las medidas de seguridad y la conducta que realiza el operario de la empresa; podría vulnerar el principio de culpabilidad si la infracción cometida por el subordinado es perpetrable únicamente a título de dolo pero la inobservancia de las medidas de seguridad por parte del titular es negligente; se cuestiona la eficacia preventiva de la sanción (multa) al poder ser ésta incorporada como costo al balance de la empresa; en todo caso, la sanción de una infracción de un deber de vigilancia no podría ser graduada, como sí lo puede la infracción de un deber de garante (según la importancia del concreto deber de garante y la importancia del bien jurídico), sino que debe resultar del mínimo común denominador de todas las infracciones imaginables del deber de vigilancia, acarreando, en consecuencia, una falta de fuerza motivadora; debido a que la infracción del deber de vigilancia se fundamenta en la inobservancia de los deberes que corresponden al titular como tal (en definitiva, una suerte de delito especial), se deja fuera de su campo de aplicación a los delitos comunes; y, al requerirse que sea un operario quien ejecuta materialmente la conducta constitutiva de delito o infracción administrativa se deja fuera del campo de aplicación del precepto, igualmente, aquellos supuestos -frecuentes , por demás, en el derecho penal de la empresa- a aquellos otros casos en que el resultado aparece como una sumatoria en donde confluyen

personal directivo no están ya comprendidos en dicho precepto, por lo que con una organización en regla de la sección interna de revisión y control del establecimiento es prácticamente imposible llegar hasta la cúspide de la empresa, sin que a su vez se pueda responsabilizar a los órganos específicos de control». Sin embargo, nosotros entendemos que si el $\$ 130 \mathrm{OWiG}$ está dirigido a "el que como titular de un establecimiento o de una empresa", se puede entender que actúa como titular no sólo quien lo es, sino también, quien no lo es pero como tal actúa, es decir, los órganos especializados de control, si bien no son titulares de un establecimiento o empresa, si quedan abarcados por el $\$ 130 \mathrm{OWiG}$ al actuar como titular. Por lo demás, el término "como" puede ser utilizado tanto como preposición equiparable a "en calidad de" y en sentido comparativo, con lo cual cabe afirmar que a todos aquellos que actúen como órgano de control instituidos y, en general como titulares de hecho, se les pueda imputar responsabilidad por la infracción del deber de vigilancia. El primero es un criterio formal del término mientras que el segundo lo es material. (Vid. Diccionario de la Lengua Española. Real Academia Española. 21ª de. Tomo I. Madrid, 1992. p. 519).

83 H. Achenbach, op. cit., p. 387 y 388. 
dos o más conductas que no responden a un plan común (una suerte de autoría accesoria).

3 Schünemann ha propuesto a modo de alternativa, un delito de peligro concreto-abstracto con el que la imprudencia del obligado a la vigilancia comprenda la contravención por él posibilitada o (según la teoría de la elevación del riesgo) facilitada, y en el que quedara comprendido el efecto de la infracción del deber de vigilancia, que va más allá de la contravención -la puesta en peligro de la seguridad en la empresa-, en forma de la «aptitud para la posibilitación de más contravenciones» ${ }^{84}$ Así, este autor propuso que sea castigado "como cómplice (o en su caso, como actor de una contravención administrativa) el que, a través de una conducta imprudente vulneradora del deber de vigilancia que le incumbe en el seno de una empresa, conforme con el $\$ 13$ StBG (o, en su caso, conforme al $\$ 8$ OWiG), facilite o haga posible la ejecución de un hecho delictivo (o, en su caso, una contravención), de una manera tal que además posea aptitud para propiciar la comisión de ulteriores delitos (o, en su caso, contravenciones).

4 En realidad no es fácil apreciar las ventajas que tendría un precepto que sancione una pura y mera infracción del deber de vigilancia en el seno de una empresa, más aún cuando se exige, de lege ferenda, que el órgano directivo haya facilitado la ejecución del hecho delictivo y que esta facilitación sea abarcada por el conocimiento y la voluntad de aquel de querer contribuir a la realización del hecho cometido por el subordinado, ya que ello sería equiparable a los supuestos de participación por omisión. Acaso, la única ventaja podría ser el de trabajar con categorías de imputación de responsabilidad penal objetiva. Así, se puede afirmar que los supuestos que se verifican en el ámbito empresarial que político-criminalmente ameritan respuesta penal se sancionan, bien como autoría o coautoría en comisión por omisión por un deber de garante respecto a los hechos ejecutados por los subordinados, bien como participación activa u omisiva en el delito que realiza el operario subordinado, sin contar el elevado riesgo de caer en una responsabilidad objetiva. Además, al tratarse de una infracción de un deber de vigilancia (mera actividad) se ha de procurar restringir su aplicación. 
Sin embargo, en caso no sea posible llevar a cabo la equiparación legal entre comisión y mera omisión -algo que depende, en definitiva, del concepto de autor que se utilice- parece lógico que se piense en la posibilidad de configurar un tipo de omisión pura sobre la base de las categorías como "producto gravemente peligroso para la vida, la salud o el medio ambiente" o "poder impedir la introducción en el mercadom. ${ }^{85}$

\section{Conclusiones y perspectivas}

1 El titular de la empresa ostenta un deber de garante que se fundamenta en el hecho de que al iniciar una actividad empresarial (configura su ámbito de dominio con exclusión de terceros) desata cursos causales respecto a los cuales tiene que evitar que lesionen bienes jurídicos y, al mismo tiempo, asume el compromiso de intervenir (controlar, contener) ante cursos causales con anterioridad a que generen lesiones a intereses penalmente relevantes. La actividad empresarial es una actividad cuyo riesgo radica en la posibilidad de que los acontecimientos que se desarrollan en mérito a ella produzcan lesiones, siendo independientes la rama o giro empresarial que se explote.

2 La responsabilidad del empresario por los hechos cometidos por sus subordinados a título de comisión por omisión se fundamenta, al igual que cualquier otro delito de comisión por omisión, en el dominio que se tiene respecto a la causa del resultado. Este planteamiento, trasladado al ámbito empresarial, importa un dominio por parte del órgano de dirección sobre las personas, y sobre los procesos y elementos de la empresa. La causalidad hipotética debe ser descartada del ámbito de los delitos omisivos y reemplazada por el criterio de incremento del riesgo.

3 Los deberes de garante del empresario tienen que ser determinados en función a la concreta situación que se valora, empero, la normativa que regula la actividad empresarial ofrece un importante indicio. Del mismo modo, criterios como "razonabilidad" y "prudencia» ofrecen parámetros para concretizar dichos deberes. La delegación en 
el ámbito empresarial genera, de cara al delegado, la asunción de una nueva posición de garante; $y$, de cara al delegante, puede generar una responsabilidad in eligiendo e in vigilando al tener que seleccionar a personas idóneas para delegar en ellas funciones materiales y/o de control, y transforma la originaria posición de garante (posición de garante residual) estando obligado, en consecuencia, a supervisar el correcto desempeño de las funciones por parte del delegado y, llegado el caso, a corregirlo y reemplazarlo. 